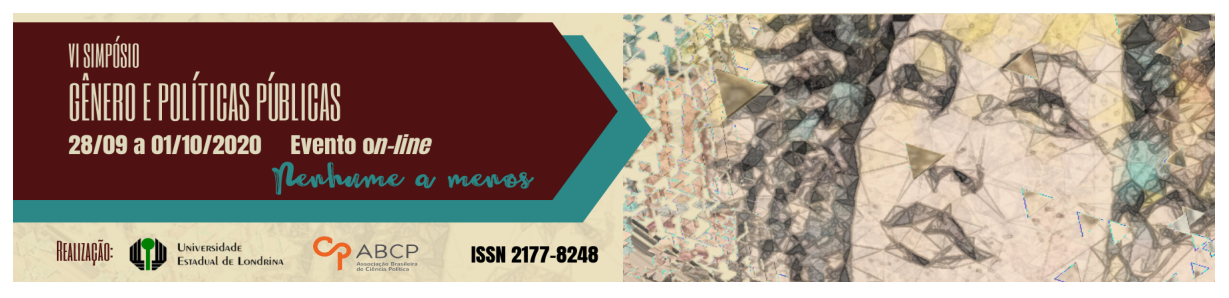

\title{
As dimensões de corpo na educação infantil: preposições históricas em relação ao determinismo biológico e ao constructo social
}

\author{
Marta Regina Furlan de Oliveiraㄹ; Ravelli Henrique de Souza ${ }^{2}$
}

\begin{abstract}
Resumo
O texto tem como objetivo principal compreender sobre as dimensões de corpo na educação infantil, considerando seus impactos e preposições históricas em relação ao determinismo biológico e ao constructo social. De modo particular, refletir como a herança corporal cultuada ao longo do tempo foi demarcada pela dicotomia biologia/cultura, propagando LGBTQ+FOBIAS e desconsiderando, desse modo, as intersecções que este transita e seus impactos educacionais. Em continuidade, essa pesquisa busca analisar o caráter normativo da Base Nacional Comum Curricular em relação a suas propostas referentes às expressões corporais na educação infantil. Para essa discussão, tem-se o seguinte questionamento: Como vem sendo constituídas as dimensões de corpo na educação infantil e, como se dá a relação entre o biológico e cultural/social nesse contexto educativo? A metodologia é um estudo bibliográfico à luz do pensamento foucaultiano e outros autores que dialogam com essa base teórica. Como resultados prévios, a escola segundo Forquin (1992) não é apenas um local em que circula fluxos humanos e coisas materiais, mas ela também é um local de gestão de transmissão de saberes e de símbolos. O corpo deve ser visto como fator central na infância, enquanto possibilidade de experiência e promoção do conhecimento plural.
\end{abstract}

Palavras-chave: educação infantil; corpo; Base Nacional Comum Curricular.

\footnotetext{
1 Universidade Estadual de Londrina. Pós-doutorado em Educação, e-mail: marta.furlan@yahoo.com.br

2 Universidade Estadual de Londrina. Mestre em Educação, e-mail: ravelli_28@hotmail.com

GT 16 - LGBTQ+Fobias e Educação: Estratificações, Resistências e Transgressões
} 


\title{
Body dimensions in early childhood education: historical prepositions in relation to biological determinism and social construct
}

\begin{abstract}
The main objective of the text is to understand the dimensions of the body in early childhood education, considering its impacts and historical prepositions in relation to biological determinism and social construct. In particular, to reflect on how the bodily heritage worshiped over time was demarcated by the biology / culture dichotomy, propagating LGBTQ + FOBIAS and disregarding, in this way, the intersections that it transits and its educational impacts. In continuity, this research seeks to analyze the normative character of the Common Base National Curriculum in relation to its proposals regarding body expressions in early childhood education. For this discussion, the following question arises: How are the dimensions of the body being constituted in early childhood education, and how is the relationship between the biological and cultural / social in this educational context? The methodology is a bibliographic study in the light of Foucault's thought and other authors who dialogue with this theoretical basis. As previous results, the school according to Forquin (1992) is not only a place where human flows and material things circulate, but it is also a place for the management of the transmission of knowledge and symbols. The body must be seen as a central factor in childhood, as a possibility of experience and promotion of plural knowledge.
\end{abstract}

Keywords: early childhood education; body; Common National Curricular Base.

\section{Introdução}

Esta pesquisa tem como objetivo principal compreender sobre as dimensões de corpo na educação infantil, considerando seus impactos e preposições históricas em relação ao determinismo biológico e ao constructo social no ocidente. Para tanto, pretende-se entender como a herança corporal cultuada ao longo do tempo foi demarcada pela dicotomia biologia/cultura, fragmentando o corpo de sua totalidade sem considerar as intersecções que este transita e seus impactos educacionais. Em continuidade, esta pesquisa busca analisar o caráter normativo da Base Nacional Comum Curricular em relação a suas propostas referentes às expressões corporais na educação infantil. 
Ainda, visa compreender as dimensões do conhecimento pela afetividade no processo de formação de professores e seus impactos na ação docente na educação para a infância, considerando as relações ao conceito de "corpo-estorvo" em um processo de descontinuidade da cultura do ódio referente à banalidade do mal e as reinvenções das "tecnologias do eu" em uma sociedade que previamente consideramos como danificada ao cegar-se em perda de sensibilidade.

Ao considerar a sociedade de forma ampla, a educação infantil, especificamente, há a percepção de um controle sobre as forças disciplinares que são constituídas nos corpos em forma de um saber. Este saber está voltado para a utilidade e docilidade, sendo denominadas por Foucault (1999) como 'tecnologia política do corpo', logo se utiliza da penalidade para administrar o controle corporal.

Os corpos que distanciam do que é imposto pelos processos formativos sociais e educacionais promove um repensar sobre uma nova conceituação sobre os mesmos, pois eles são tratados como instrumento ou recurso pedagógico que devem ser a todo momento disciplinados. $\mathrm{O}$ corpo visto como natural ignora as questões sociais de classe, cultura, raça, etnia, gênero e sexualidade. Assumindo uma concepção totalmente homogeneizada da educação impactando de maneira significativa na formação/ação docente. Esse corpo é utilizado como alvo de práticas disciplinares para atingir comportamentos estereotipados pela escola, fundamentados pelas diferenças das características físicas e biológicas, ignorando, assim, o fator cultural que é construído.

A educação infantil diante dos dispositivos legais que a circulam é considerada como a primeira etapa da educação básica "e tem como finalidade o desenvolvimento integral das crianças de zero a seis anos de idade em seus aspectos físico, afetivo, intelectual, linguístico e social" (BUSS-SIMÃO, 2016, p. 185). A Base Nacional Comum Curricular (BNC) também propõe para essa etapa de ensino uma organização por meio de Campos de Experiencias de modo a garantir o conhecimento de si e do outro entre professores e alunos 
através de fatores que permeiam a natureza e a cultura. Assim, neste estudo pretendemos analisar a questão corporal relacionada ao campo de experiencias da BNC, para que possamos pensar esse corpo não só como biológico ou construído socialmente, mas sim com mutua relação entre ambos fatores. $\mathrm{O}$ corpo deve ser visto como fator central na educação infantil, de modo que ele garante experiencia e permite a promoção do conhecimento quando visto como plural.

\section{A questão afetiva no ambiente educacional e seus impactos na formação docente}

Em pleno século XXI, tempos ditos como contemporaneos a profissionalização docente se encontra em um período considerado por Arendt (2013) como sombria, sendo constantemente atacada pela banalidade do mal. Segundo a autora o mal banal se define por atos superficiais, ele não é uma fatalidade, mas sim uma possibilidade de "libertação humana". Se enraíza em pessoas incapazes de pensar sobre seus próprios atos, ele é burocrático, sistemático e eficiente, pois provém de uma norma, de uma tradição hegêmonica.

Se direcionarmos toda essa questão para os campos de formação e ação docente, teremos a ideia de 'semiformação' proposta por Adorno (1995) que justifica-se como uma falsa formação, propícia ao pensamento supersticioso, que, através de conteúdos instrumentalizados, forma indivíduos exclusivamente para a adaptação aos moldes de uma sociedade danificada e administrada. Logo, a educação, através da experiência e do conhecimento construído, deve fazer relação entre objeto e sujeito voltados contra a barbárie, de forma a não aprisionar o objeto à relação com o sujeito, permitindo que a objetividade humana seja ressignificada pela subjetividade das identidades para uma formação justa e emancipada dos sujeitos.

Toda essas questões mencionadas acima são proporcionadas pela falta ou exarcebo da questão afetiva na educação, de modo que, tanto professores, como alunos, sendo seres humanos carecem do afeto 
como conhecimento para dar sentido e significado nas relações humanas e educativas. Segundo Martins (2009) o conhecimento é o mais importante dos afetos, pois, com a reflexão deste percebemos que podemos nos afetar de diversas maneiras, sendo elas boas e/ou ruins

O afeto conhecimento permite a não exclusão das identidades em nosso ambiente de estudo e trabalho, pois, quando um professor em sua formação é educado por afeto, em seu momento de ensino o mesmo transmitirá esse conhecimento, que deve ser obrigatório e importante para formação crítica e emancipada de seus alunos.

Em um movimento contrário, os documentos legais da educação, assim como a BNC que priorizamos como nosso objeto de estudo, não apontam a importancia da valorização afetiva na formação docente e nos campos de experiencias, logo, são categorizadas funções normativas à professores e alunos, que são tratados a todo momento como instrumentos aptos a seguirem regras e orientações curriculares instrumentalizadas. Há um controle sobre as forças disciplinares constituídas nos corpos de forma que há um saber sobre estes, que não necessariamente possa ser uma ciência, pois este saber está voltado para utilidade e docilidade. Essas forças são denominadas por Foucault (1999) como 'tecnologia política do corpo', logo se utiliza da penalidade para administrar o controle corporal.

Assim sendo, os corpos que fogem do que é imposto nestes documentos legais nos permitem criar uma nova conceituação sobre os mesmos, pois eles são tratados como instrumento ou recurso pedagógico que devem ser a todo momento disciplinados, eles estorvam. Nesta concepção de "corpo estorvo" previamente citado por Buss-Simão (2016), entendemos que:

O corpo precisa ser treinado para aprender a segurar o lápis, os talheres de forma correta, aprender a sentar e permanecer imóvel para fazer a atividade, e ainda, por outro lado, um corpo que precisa cansar ou ficar calmo para a realização das atividades consideradas "mais nobres", que numa concepção dicotômica e fragmentada, valoriza mais a cognição. Esse "corpo como estorvo" é também 
um corpo que incomoda, que não tem domínio sobre os movimentos, que se movimenta demais, que não se aquieta para desenhar, pintar, escrever, dormir e, por isso, precisa, por um lado ser treinado e, por outro, primeiramente, usar sua energia correndo, pulando, dançando, dramatizando para ficar cansado, e então, ser mais útil para as atividades consideradas cognitivas e intelectuais, tradicionalmente concebidas como "mais nobres" (BUSS-SIMÃO, 2016, p. 165).

Esses corpos se fluem pelo espaço e materializam as normas estabelecidas perante seu sexo biológico, com a submissão e obediência de pura coerção: "obedecemos àquele que tem nas mãos a arma ou o chicote, a força de decisão sobre a carreira e mesmo sobre a vida e a morte" (GROS, 2018, p.38). O que gera grandes impactos na formação e ação docente, fazendo necessário o movimento de estranhamento dos documentos legais da educação, tal como a BNC, para que possamos elencar os desafios e repensar as afetividades e possibilidades da formação e ação docentes vistas como plurais e não homogêneas.

\section{Os campos de experiências na Base Nacional Comum Curricular: corpos que estorvam}

Ao refletir sobre a temática Campos de Experiências propostos pela Base Nacional Comum Curricular (BNC) para a educação infantil, percebe-se que as experiências de aprendizagem devem proporcionar situações pautadas nas múltiplas formas de experiências e conhecimento em confluências com a diversidade cultural encontrada na escola infantil. O conjunto de práticas pedagógicas segundo o documento deve buscar articular os saberes de modo que englobe conhecimento, cientifico, tecnológico e os que envolvem a natureza, a cultura e as artes (BRASIL, 2015). Desse modo, o arranjo curricular denominado como campos de experiências da BNCI: base nacional comum curricular da educação infantil, engloba: “o eu, o outro e o nós”, ofertando às crianças "a oportunidade de estabelecer ações e 
relações com pessoas, espaços, tempos, objetos, situações e atribuir um sentido pessoal e social a eles" (BUSS-SIMÃO, 2016, p. 196). De maneira que:

Compreender as experiências sensoriais, expressivas, corporais e de movimento como constituintes do Campo de Experiência: o eu, o outro e o nós, requer compreender os conhecimentos com o corpo para perceber, conhecer e significar as sensações, funções e movimentos internos do corpo. Implica também compreender o corpo como um território inviolável e olhar para o corpo e sua relação com os processos de socialização, interação e emoção, em que a constituição do corpo se dá num entrelaçamento com a emoção, a cognição e a linguagem, pois a visão que temos do nosso corpo, as formas como sentimos esse corpo vem da relação com o outro (BUSS-SIMÃO, 2016, p. 198).

Os campos de experiência tratam sobre as questões corporais em que daremos destaque em nossa pesquisa, pois, historicamente na cultura ocidental a concepção de criança e corpo foi demarcada primeiramente como natural e biológica, em que deu embasamento a uma infância homogênea e institucionalizada. E no decorrer da história, aparece as concepções de corpo demarcadas como culturais, provenientes de uma herança social e histórica. Ambas as concepções, mesmo em tempos contemporâneos vem sendo estudas separadamente, impossibilitando as mútuas relações entre ambas.

O corpo visto como natural ignora as questões sociais de classe, cultura, etnia, gênero e sexualidade. Assumindo uma concepção totalmente homogeneizada da educação impactando de maneira significativa na formação e ação docente. Este corpo é utilizado como alvo de práticas disciplinares para atingir comportamentos adequadamente estereotipados pela escola, fundamentados pelas diferenças das características físicas e biológicas, ignorando, assim, o fator cultural que é construído.

As experiências propostas pela BNCI dizem a respeito do conhecimento de si e do outro para as crianças tenham a garantia de 
"conviver, brincar, explorar, participar, expressar e conhecer-se" (BUSS-SIMÃO, 2016, p.196). Ainda que as práticas educativas devem ocorrer em conjunto. A partir dessa leitura, percebe-se que ao mascarar-se de inclusivo o arranjo curricular da BNCI junto as suas práticas de experiências corporais negam o pluralismo de identidades apresentando um caráter normativo. Uma vez que não trata das questões relacionadas às interseccionalidades.

Com essas questões postas na BNC os professores que as adquirem, ao tentar tratar os alunos todos como iguais se tornam incapazes de se relacionar com os alunos identificados como os "outros", negando-os, colocando-os em posição de estorvo, de "abjeto". Butler (2017) ao tratar da 'ilegitimidade' dos corpos, denominou-os como "corpos abjetos", isto é, "corpos deslegitimados", que "deixam de contar como corpos" porque não fazem parte do "esperado para o seu sexo".

O abjeto, está relacionado à moldagem de um corpo tratado como plástico que funciona em uma grande performance visual de consenso orquestrado, é tratado como um corpo morto, marginalizado e inexistente (TIBURI, 2017). De maneira que, a construção política do sujeito procede vinculada a certos "objetivos de legitimação e de exclusão, essas operações políticas são efetivamente ocultas e naturalizadas por uma análise política que toma as estruturas jurídicas como seu fundamento" (BUTLER, 2017, p. 19).

É digna a percepção de que essas questões ditas pela BNCC e seu caráter normativo são apenas jogos manipulativos, pois, segundo Butler (2017), não faz sentido definir o gênero como interpretação cultural do sexo, uma vez que é plural entre significados culturais reconhecidos pelo corpo sexuado e, este corpo não decorre do sexo para se construir exclusivamente como masculino ou feminino. A "verdade" binária do sexo é produzida pelas normas regulatórias da sociedade disciplinar a fim de gerar identidades hegemônicas (FOUCAULT, 2003). 
É desta discussão entre as dicotomias do corpo natural/cultural, normal/abjeto que nos dão embasamento a criação do corpo como estorvo, pois este precisa de uma educação para disciplina-lo, então ele é colocado em uma redoma de modo que ele sai de uma lógica binária que incomoda o sistema escolar. Ele a todo momento está estorvando e é muito mais extenso que o corpo abjeto, pois ultrapassa as questões de gênero. Mesmo que também marginalizado ele é visto, incomoda e é incomodado pelo simples fato de existir e permitir. $\mathrm{O}$ corpo estorvo é cego, surdo, deficiente, pobre, rico, heterossexual, homossexual, transexual, branco, negro, periférico, adoecido, etc. Ele é a junção mutua entre corpo natureza e corpo cultural e pode ser qualquer corpo que foge dos padrões normativos impostos pelos dispositivos legais da educação e das normais de comportamento. Deste modo, consideramos o corpo estorvo como categoria de análise para pesquisas relacionadas a formação e ação docente.

\section{A importância da teoria queer para os corpos que estorvam: estranhando o binarismo de gênero no ambiente educacional}

A Teoria Queer pode ser considerada como uma abordagem interdisciplinar do estudo da sexualidade, contribuindo significativamente com os estudos culturais, porém essa teoria é dotada de complexidade, apresentando múltiplos conceitos, permitindo diversas interpretações que se fluem e se complementam.

A palavra 'queer' é um ato da revolta de Stonewall das pessoas homossexuais contra o sistema policial homofóbico, que as tratava como estranhos, de modo pejorativo, ou seja, corpos que estorvam. Assim sendo, queer se tornou uma palavra de resistência contra a homofobia, em que pessoas não heterossexuais se assumiram como queers para afrontar o sistema e lutar por seus direitos. Assim sendo, queer significa basicamente em se opor ou desafiar e estorvar a norma, o sistema. 
Em consonância com (MISKOLCI, 2009) o discurso proposto pela Teoria Queer em confluências com a sociologia foi marcado pelo estranhamento e pela afinidade em relação a construção social e histórica da sexualidade. $\mathrm{O}$ estranhamento queer rompe com a relação social e biológica que até a década de 1990 tratavam as questões de gênero como determinismo heterossexual não-hegemônico. Dessarte, os estudos sobre o pluralismo e multiplicidade de identidades de gênero questionam os pressupostos normalizadores do século XXI, que oprimem os sujeitos e suas subjetividades humanas tratadas como corpos estorvos.

Com essas questões postas, os profissionais educacionais que adquirem ao determinismo biológico de gênero, ao tentar tratar os alunos todos como iguais, tornam-se incapazes de se relacionar com os alunos identificados como "estranhos", negando-os, colocando-os em posição de estorvo, de "abjeto".

É desta discussão entre as concepções de gênero, corpo estorvo e teoria queer, que devemos visar uma nova proposta pedagógica incrivelmente inovadora, fazendo necessário o movimento de estranhamento dos documentos legais da educação escolar, tal como a Base Nacional Comum Curricular, para que possamos elencar os desafios e repensar as afetividades e possibilidades da formação e ação docente vistas como plurais e não homogêneas.

\section{Considerações finais}

O corpo, em sua centralidade na discussão feita sobre as identidades múltiplas e subjetivas dos sujeitos, deve se pensar a relação de dentro para fora, como um ato revolucionário, uma vez que todos somos possuintes de corpo em totalidade. Todos temos direitos iguais e devemos quebrar com a lógica binária a partir do conhecimento e relato de si, para que possamos ouvir e respeitar ao outro. 
No ambiente educacional, quando, a partir do processo de ensino e aprendizagem, entendemos a temática de identidade de gênero e educação sexual, nós aprendemos sobre nós mesmos, sobre nosso corpo e a construção de nossa identidade, o que promove um senso crítico inclusivo na própria pessoa que começará a entender o outro como diferente, mas com direitos humanos iguais. Com isso, é possível formar alianças estudantis para rompermos com a barreira do preconceito.

Sendo assim, constatamos que a escola segundo Forquin (1992) não é apenas um local em que circula fluxos humanos e coisas materiais, mas ela também é um local de gestão de transmissão de saberes e de símbolos. Tendo isso, Gatti (2010) afirma que estamos assumindo o papel da escola e dos professores o de ensinar educando, uma vez que sem conhecimentos básicos para a interpretação do mundo não há uma condição verdadeira para a formação de valores e exercício da cidadania. A profissionalização de professores para Gatti implica na obtenção de um espaço autônomo, própria à sua profissão, com um valor reconhecido pela sociedade que não continue desvalorizando a profissão em múltiplos aspectos e que se constitua uma base sólida de conhecimentos e formas de ação.

Reconhecer as diferenças é questionar os conceitos homogêneos, estáveis e permanentes que excluem o que é estranho dos padrões normativos. Todas essas certezas que foram construídas ao longo do tempo devem se fragilizar e desvanecer, pois é necessário desconstruir, pluralizar, ressignificar, reinventar identidades e subjetividades, saberes, valores, convicções e horizontes de sentidos.

É preciso respeitar as diferenças para que não haja mais exclusões e discriminações e comprimam as possibilidades de intervenção junto ao sujeito e sua constituição como sujeito social. Assim, faz-se necessário valorizar as diferenças culturais e sociais e suas diversificações de meninas e meninos no ambiente escolar, com tais procedimentos: questionar afirmativas sobre sexualidades que rotulam os seres não binários; quebrar o tabu do estereótipo superficial 
e masculinizado imposto nas meninas; valorizar a capacidade do ser humano sem fazer distinções de gênero; respeitar as diferenças entre feminilidades e masculinidades; refletir, conversar e intervir sobre piadas e brincadeiras que agridem o outro; respeitar a diversidade cultural, social e sexual; evitar o uso de linguagens preconceituosas e discriminatórias; pensar em diversas situações que envolvam corpo, gênero, sexo e sexualidade que promovam o respeito pela diversidade.

\section{Referências}

ADORNO, Theodor W. Educação - para quê? In: ADORNO, T. W. Educação e emancipação. Rio de Janeiro. Paz e Terra, 1995.

ARENDT, Hannah. Entre o passado e o futuro. 7. ed. 1. reimp. São Paulo: Perspectiva, 2013.

BRASIL. Ministério da Educação. Base nacional comum curricular. Brasília, DF: MEC, 2015. Disponível em: <http:/ / basenacionalcomum.mec.gov.br/documento/BNCCAPRES ENTACAO. pdf>. Acesso em: 30 out. 2015.

BUSS-SIMÃO, Marcia. Experiências Sensoriais, Expressivas, Corporais e de Movimento nos campos de Experiências da Base Nacional Comum Curricular para Educação Infantil. Debates em Educação, Maceió, v. 8, n. 16, jul./dez. 2016.

BUTLER, Judith. Problemas de Gênero: feminismo e subversão da identidade. Tradução de Renato Aguiar. 15 ed. Rio de Janeiro: Civilização Brasileira, 2017.

FORQUIN, Jean-Claude. Saberes escolares, imperativos didáticos e dinâmicas sociais. Teoria E Educação, n. 05, p. 28-49, 1992.

FOUCAULT, Michel. A Microfísica do Poder. Organização e tradução: Roberto Machado. Rio de Janeiro: Edições Graal, 1999.

FOUCAULT, Michel. História da sexualidade. A vontade de saber. São Paulo: Paz \& Terra, 2003. v.1.

GATTI, Bernadete. A Formação de Professores no Brasil: características e problemas. Educ. Soc., Campinas, v. 31, n. 113, p. 1355-1379, 2010. 
GROS, Frédéric. Desobedecer. Tradução: Célia Euvaldo. São Paulo: Ubu Editora, 2018.

MARTINS, André. O mais potente dos afetos: Spinoza \& Nietzsche. São Paulo: Editora WMF Martins Fontes, 2009.

MISKOLCI, R. A Teoria Queer e a Sociologia: o desafio de uma analítica da normalização. Sociologia, ano 11, n. 21, p.150-182, 2009.

TIBURI, Marcia. Ridículo político: uma investigação sobre o risível, a manipulação da imagem e o esteticamente correto. 2. ed. Rio de Janeiro: Record, 2017. 